Published in final edited form as:

Inorg Chem. 2018 October 01; 57(19): 12323-12330. doi:10.1021/acs.inorgchem.8b02021.

\title{
ENDOR characterization of $\left(\mathrm{N}_{2}\right) \mathrm{Fe}$ model for $\mathrm{N}_{2}$ binding by the di- $\mu$-hydrido nitrogenase Janus intermediate
}

\author{
Hao Yang ${ }^{\S}$, Johnathan Rittle ${ }^{\curvearrowright, \#}$, Amy R. Marts ${ }^{\S}$, Jonas C. Peters ${ }^{\curvearrowright,}$, , Brian M. Hoffman ${ }^{\S, *}$ \\ 'Department of Chemistry, Northwestern University, Evanston, IL 60208, USA \\ rDivision of Chemistry and Chemical Engineering, California Institute of Technology (Caltech), \\ Pasadena, California 91125, USA
}

\begin{abstract}
The biomimetic diiron complex 4-( $\left.\mathbf{N}_{2}\right)_{2}$, featuring two terminally bound $\mathrm{Fe}-\mathrm{N}_{2}$ centers bridged by two hydrides, serves as a model for two possible states along the pathway by which the enzyme nitrogenase reduces $\mathrm{N}_{2}$. One is the Janus intermediate, $\mathrm{E}_{4}(4 \mathrm{H})$ which has accumulated $4[\mathrm{e}-/ \mathrm{H}+]$, stored as two [Fe-H-Fe] bridging hydrides, and is activated to bind and reduce $\mathrm{N}_{2}$ through reductive elimination ( $r e$ ) of the hydride ligands as $\mathrm{H}_{2}$. The second is a possible re intermediate. ${ }^{1} \mathrm{H}$ and ${ }^{14} \mathrm{~N} 35 \mathrm{GHz}$ ENDOR measurements confirm that the formally ' $\mathrm{Fe}(\mathrm{II}) / \mathrm{Fe}(\mathrm{I})$ ' $4-\left(\mathbf{N}_{\mathbf{2}}\right)_{\mathbf{2}}$ complex exhibits a fully delocalized, Robin-Day type III mixed valency. The two bridging hydrides exhibit a fully rhombic dipolar tensor form, $\mathbf{T} \approx[-\mathrm{t},+\mathrm{t}, 0]$. The rhombic form is reproduced by a simple point-dipole model for dipolar interactions between a bridging hydride and its 'anchor' Fe ions, confirming validity of this model, and demonstrating that, observation of a rhombic form is a convenient diagnostic signature for the identification of such core-structures in biological centers such as nitrogenase. Furthermore, interpretation of the ${ }^{1} \mathrm{H}$ measurements with the 'anchor' model maps the $\mathrm{g}$ tensor onto the molecular frame, an important function of these equations for application to nitrogenase. Analysis of the hyperfine and quadrupole coupling to the bound ${ }^{14} \mathrm{~N}$ of $\mathrm{N}_{2}$ provides a reference for nitrogen-bound nitrogenase intermediates, and is of chemical significance, as it gives a quantitative estimate of the amount of charge transferred between $\mathrm{Fe}$ and coordinated $\mathrm{N}$, a key element in $\mathrm{N}_{2}$ activation for reduction.
\end{abstract}

\section{Graphical Abstract}

*Corresponding Authors jpeters@caltech.edu, bmh@ northwestern.edu.

\#Current Address: Department of Chemistry and Biochemistry, University of California, Berkeley, Berkeley, CA USA Supporting information

PESTRE measurement for ${ }^{1} \mathrm{H}$ and ${ }^{31} \mathrm{P}$; the simulation sum of ${ }^{31} \mathrm{P}$ ENDOR for $\mathrm{P}_{\mathrm{A}}$ and $\mathrm{P}_{\mathrm{B}}$; the simulation of the full $2 \mathrm{D}$ pattern of

${ }^{14} \mathrm{~N}$ ENDOR, and $\mathrm{X}$-band ${ }^{14} \mathrm{~N}$ ESEEM and simulations.

The authors declare no competing financial interest. 


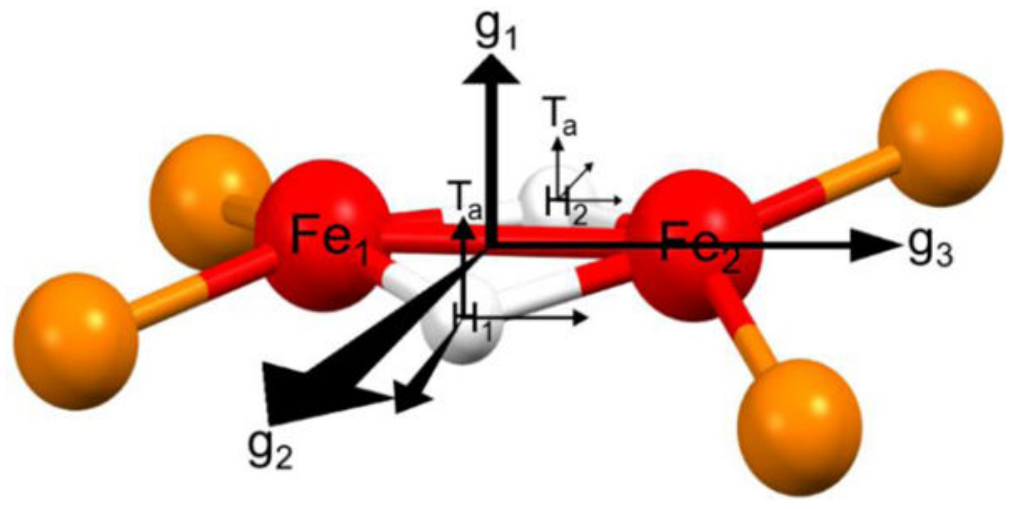

\section{Synopsis}

The biomimetic diiron complex $4-\left(\mathbf{N}_{2}\right)_{2}$ models a possible intermediate in the activation of nitrogenase by reductive elimination of two [Fe-H-Fe] bridging hydrides with $\mathrm{N}_{2}$ binding by the key $\mathrm{E}_{4}(4 \mathrm{H})$ Janus intermediate. The comprehensive ENDOR characterization of the rare 4-( $\left.\mathbf{N}_{\mathbf{2}}\right)_{2}$ core structure confirms both the hydride anisotropic hyperfine tensor as a diagnostic signature of this moiety in biological centers, and an analytical analysis of the tensor that has an important function in studies of nitrogenase.

\section{Introduction}

Biological nitrogen fixation - the reduction of $\mathrm{N}_{2}$ to two $\mathrm{NH}_{3}$ molecules - sustains life and involves perhaps the most challenging chemical transformation in biology, the reduction of the $\mathrm{N} \equiv \mathrm{N}$ triple bond. The catalyst for biological $\mathrm{N}_{2}$ fixation is the metalloenzyme nitrogenase, composed of the electron-donating Fe protein and the catalytic MoFe protein, with reduction of $\mathrm{N}_{2}$ at the FeMo-cofactor (FeMo-co) active site of the MoFe protein, [7Fe-9S-Mo-C-homocitrate], on the specific $4 \mathrm{Fe}$-face picture in Figure $1 .{ }^{1-5}$

In recent years, Hoffman, Seefeldt, Dean and coworkers have shown ${ }^{6-10}$ that activation of nitrogenase for $\mathrm{N}_{2}$ reduction involves the accumulation of four reducing equivalents at the active site FeMo-co to form a state with two [Fe- $\mathrm{H}-\mathrm{Fe}]$ bridging hydrides and two sulfurbound protons (denoted $\mathrm{E}_{4}(4 \mathrm{H})$, the Janus intermediate). Subsequent binding and reduction of $\mathrm{N}_{2}$ requires the reductive elimination (re) of $\mathrm{H}_{2}$ from $\mathrm{E}_{4}(4 \mathrm{H})$. This process corresponds to the forward direction of the equilibrium formation of the intermediate, $\mathrm{E}_{4}(2 \mathrm{~N} 2 \mathrm{H})$ at the diazene level, with FeMo-co having accumulated $\mathrm{N}_{2}$ and $2\left(\mathrm{e}^{-} / \mathrm{H}^{+}\right)$, Figure 2, whose reverse is the oxidative addition (oa) of $\mathrm{H}_{2}$ with release of $\mathrm{N}_{2}$. This re/oa equilibrium is nearly thermoneutral,

$$
E_{4}(4 \mathrm{H})+\mathrm{N}_{2} \rightleftarrows E_{4}(2 \mathrm{~N} 2 \mathrm{H})+\mathrm{H}_{2}, \Delta G^{0} \approx-2 \mathrm{kcal} / \mathrm{mol}
$$

and kinetically reversible. ${ }^{9}$ Whereas direct hydrogenation, $\mathrm{N}_{2}+\mathrm{H}_{2} \rightarrow \mathrm{N}_{2} \mathrm{H}_{2}$, is highly endergonic $(>+50 \mathrm{kcal} / \mathrm{mol}$ in the gas phase), this equilibrium is rendered thermoneutral by mechanistic coupling of the unfavorable binding and reduction of $\mathrm{N}_{2}$ to the highly favorable 8,9,11-13 generation of $\mathrm{H}_{2}$ driven by the ATP hydrolysis associated with electron delivery 
from the $\mathrm{Fe}$ to the $\mathrm{MoFe}$ protein, ultimately leading to cleavage of the $\mathrm{N} \equiv \mathrm{N}$ triple bond. $8,9,14$

This mechanistic picture highlights the need for well-defined model complexes that might possess key spectroscopic signatures of nitrogenase intermediates that arise in the re/oa transformations. ${ }^{7}$ As shown in Chart 1 , multiple potential mechanisms can be envisaged for this process. The 'dissociative' process has been ruled out by well-known properties of nitrogenase turnover under atmospheres of $\mathrm{N}_{2}$ and $\mathrm{D}_{2} / \mathrm{T}_{2} \cdot{ }^{11}$ Detailed analysis of the photolysis of $\mathrm{E}_{4}(4 \mathrm{H})$ has indicated that an $\mathrm{H}_{2}$ complex appears as an intermediate, $\mathbf{Y}$, in the reductive elimination process, but whether $\mathrm{N}_{2}$ binds to $\mathrm{E}_{4}$ prior to, or in a concerted step concomitant with, $\mathrm{H}_{2}$ formation has not been determined; 9,12 recent DFT studies indicate that $\mathrm{N}_{2}$ binds to the $\mathrm{H}_{2}$ complex in an 'Intermediate' mechanism (Chart 1). ${ }^{13}$

Inspired by the multimetallic FeMo-co of nitrogenase, dinuclear iron complexes with multiple accessible redox states have been targeted as structural and functional models relevant to multielectron $\mathrm{N}_{2}$ reduction. ${ }^{15-19}$ In this context, Rittle, McCrory, and Peters have described a diiron(II) di hydride-bridged system, $\left(\mathrm{Fe}^{\mathrm{II}}(\mu-\mathrm{H})_{2} \mathrm{Fe}^{\mathrm{II}}\right)$, with a high affinity for binding $\mathrm{N}_{2}$ in its $S=0$ ground state $\left(\mathrm{Fe}^{\mathrm{II}}(\mu-\mathrm{H})_{2} \mathrm{Fe}^{\mathrm{II}}\left(\mathrm{N}_{2}\right)\right)$. A second equivalent of $\mathrm{N}_{2}$ binds weakly as observed by IR, UV-vis, and Mössbauer spectroscopies.

$$
\mathrm{N}_{2}+\mathrm{Fe}^{\mathrm{II}}(\mu-\mathrm{H})_{2} \mathrm{Fe}^{\mathrm{II}}\left(\mathrm{N}_{2}\right) \rightleftarrows\left(\mathrm{N}_{2}\right) \mathrm{Fe}^{\mathrm{II}}(\mu-\mathrm{H})_{2} \mathrm{Fe}^{\mathrm{II}}\left(\mathrm{N}_{2}\right) \mathrm{K}_{\mathrm{eq}}(298 \mathrm{~K})=1.1 \mathrm{M}^{-1}
$$

Chemical reduction generates a state with dramatically enhanced binding affinity for a second $\mathrm{N}_{2}$ equivalent, providing the EPR-active $S=1 / 2$ complex $\left(\mathrm{N}_{2}\right) \mathrm{Fe}^{\mathrm{II}}(\mu-\mathrm{H})_{2} \mathrm{Fe}^{\mathrm{I}}\left(\mathrm{N}_{2}\right)^{-}$ $\left(\mathbf{N}_{2}\right)_{2}$; see Chart 1).

$$
\mathrm{N}_{2}+{ }^{“}\left[\mathrm{Fe}^{\mathrm{I}}(\mu-\mathrm{H}){ }_{2} \mathrm{Fe}^{\mathrm{II}}\left(\mathrm{N}_{2}\right)\right]^{-} " \rightleftarrows\left[\left(\mathrm{N}_{2}\right) \mathrm{Fe}^{\mathrm{I}}(\mu-\mathrm{H})_{2} \mathrm{Fe}^{\mathrm{II}}\left(\mathrm{N}_{2}\right)\right]^{-}\left[4-\left(\mathrm{N}_{2}\right)_{2}\right] \mathrm{K}_{\mathrm{eq}}(298 \mathrm{~K}) \sim 10^{6} \mathrm{M}^{-1}
$$

While the latter is formally mixed-valent, DFT computations predicted symmetric spin density delocalization between the two iron centers. The electron density was concentrated

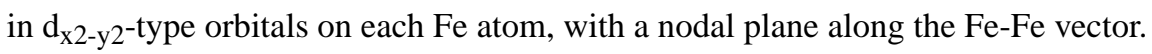
Additionally, there was a significant amount of spin polarization onto the bridging hydride and $\mathrm{N}_{2}$ ligands ligands. Indeed, the largest hyperfine coupling observed in the X-band EPR spectrum at $77 \mathrm{~K}$ was attributed to the bridging hydrides, confirmed by the corresponding spectrum for $\left(\mathrm{N}_{2}\right) \mathrm{Fe}^{\mathrm{II}}(\mu-\mathrm{D}){ }_{2} \mathrm{Fe}^{\mathrm{I}}\left(\mathrm{N}_{2}\right)^{-} \cdot{ }^{20}$

Herein we undertake further characterization of the 4-( $\left.\mathbf{N}_{\mathbf{2}}\right)_{\mathbf{2}}$ mixed-valence ' $\mathrm{Fe}(\mathrm{II}) \mathrm{Fe}(\mathrm{I})$ ' complex through a detailed electron-nuclear double resonance (ENDOR) analysis of ${ }^{1,2} \mathrm{H}$, ${ }^{31} \mathrm{P}$ and ${ }^{14} \mathrm{~N}$ ENDOR measurements. Firstly, this complex serves as a structurally useful model of the possible nitrogenase intermediate, ' $\mathbf{Y}$ ' of the 'Associative' re activation process (Chart 1). Secondly, the disposition of the hydrides in the $\mathrm{E}_{4}(4 \mathrm{H})$ intermediate is not definitively known and one currently proposed alternative model has both of them bridging a pair of Fe ions, ${ }^{21}$ as in this complex, so characterization of these hydrides is important. This 
issue is currently under investigation in our laboratory, in studies that use an analytical description of the hyperfine tensors of bridging hydrides, ${ }^{22}$ and this complex provides a further test of this description that complements an earlier study of a mixed-valence ' $\mathrm{Fe}(\mathrm{II}) \mathrm{Fe}(\mathrm{I})$ ' complex with bridging hydride and [-NH-]. ${ }^{23}$ Thirdly, characterization of the hyperfine and quadrupole couplings to the bound $\mathrm{N}_{2}$ provides the first opportunity to compare the properties of nitrogen-bound nitrogenase intermediates ${ }^{6,7}$ with those of a structurally defined model. Finally, these measurements provide an opportunity to further characterize the $\mathrm{Fe}-\mathrm{Fe}$ delocalization, and $\mathrm{Fe}-\mathrm{N}_{2}$ and [Fe-H-Fe] bonding.

\section{Methods}

EPR/ENDOR samples of 4-( $\left.\mathbf{N}_{\mathbf{2}}\right)_{\mathbf{2}}$ were prepared in an $\mathrm{N}_{2}$ filled dry-glove box as described previously. ${ }^{20}$ However, in that study, samples for EPR were prepared as $5 \mathrm{mM}$ solutions in 2Me-THF. In the present study, we opted for samples at $1 \mathrm{mM}$ concentrations in 1:5 solvent mixture of THF:toluene. The solvent difference leads to subtle differences in X-band EPR spectra.

$35 \mathrm{GHz} \mathrm{CW}$ and pulse ENDOR spectroscopic data were collected on spectrometers, described previously, ${ }^{24-26}$ that were equipped with liquid helium immersion dewars for measurements at $2 \mathrm{~K}$. The $\mathrm{CW}$ measurements employed $100 \mathrm{kHz}$ field modulation and dispersion mode detection under rapid passage conditions. ${ }^{1} \mathrm{H}$ CW ENDOR spectra employed broadening of the RF to $100 \mathrm{kHz}$ to improve signal-to-noise. ${ }^{27}{ }^{1} \mathrm{H} \mathrm{CW}$ ENDOR spectra were collected using the stochastic-field modulation detected ENDOR sequence, ${ }^{28}$ to improve ENDOR line shape. For a single molecular orientation and for nuclei with nuclear spin of $\mathrm{I}=1 / 2\left({ }^{1} \mathrm{H},{ }^{31} \mathrm{P}\right)$, the ENDOR transitions for the $\mathrm{m}_{\mathrm{s}}= \pm{ }^{1} / 2$ electron manifolds are observed, to first order, at frequencies, where $v_{\mathrm{n}}$ is the nuclear Larmor frequency, and $\mathrm{A}$ is the orientation-dependent hyperfine coupling. For I $\geq 1\left({ }^{2} \mathrm{H},{ }^{14} \mathrm{~N}, \mathrm{I}=1\right)$, the two ENDOR lines are further split by the orientation-dependent nuclear quadrupole coupling $(\mathrm{P})$ into 2I lines given by equation:

$$
\begin{gathered}
I=1 / 2: v_{ \pm}=\left|v_{\mathrm{n}} \pm \frac{A}{2}\right| \quad(1 \mathrm{a}) \\
I \geq 1: v_{ \pm}=\left|v_{\mathrm{n}} \pm \frac{A}{2} \pm\left(\frac{3 P\left(2 \mathrm{M}_{\mathrm{I}}\right)-1}{2}\right)\right|
\end{gathered}
$$

In the Mims experiment, the ENDOR intensities are modulated by an inherent response factor $(\mathrm{R})$,

$$
\mathrm{R} \sim[1-\cos (2 \pi \mathrm{Ag} \tau)]
$$


Where $\tau$ is the interval between the first and second pulses in the three-pulse Mims. When $\mathrm{A} \tau=\mathrm{n}(\mathrm{n}=0,1,2 \ldots)$, the ENDOR response is at a minimum, resulting in hyperfine 'suppression holes' in the Mims spectra.

At the low and high field edges of the EPR spectrum ( $g_{1}$ and $g_{3}$, respectively), ENDOR interrogates only a single molecular orientation ('single-crystal-like' position). At intermediate fields, however, ENDOR interrogates a well-defined subset of molecular orientations. By analyzing a 2D field-frequency pattern of ENDOR spectra collected across the EPR envelope, it is generally possible to determine the complete hyperfine and quadrupole tensors and their orientations relative to g. ${ }^{29,30}$ The absolute signs of the hyperfine couplings measured from ENDOR spectra (more specifically, the sign of

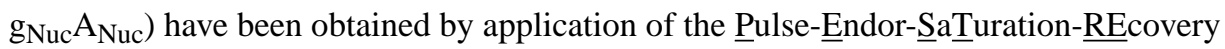
(PESTRE) protocol, described previously. ${ }^{31}$

\section{Results and Discussion EPR Spectra of $4-\left(\mathbf{N}_{2}\right)_{2}$.}

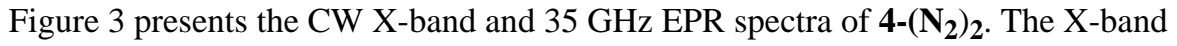

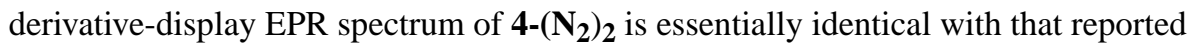
previously, and is characteristic of a spin $S=1 / 2$ system with nearly axial g-tensor $\mathrm{g}=$ $[2.148,2.057,2.030]$. The derivative display $35 \mathrm{GHz}$ CW EPR spectrum (numericalderivative of $2 \mathrm{~K}$ dispersion rapid-passage absorption-display spectrum) clearly displays the presence of a small rhombic splitting to the $\mathbf{g}$ tensor (Fig 3). Simulation of this spectrum yields $\mathbf{g}=[2.156,2.063,2.036]$, a refinement of the previous values based on simulation of the X-band EPR spectra. The ${ }^{1} \mathrm{H}$ and ${ }^{14} \mathrm{~N}$ ENDOR measurements presented below orient $\mathbf{g}$ in the molecular frame, in particular independently showing that $\mathrm{g}_{1}$ corresponds to the orientation normal to the $\left[\mathrm{Fe}(\mathrm{H})_{2} \mathrm{Fe}\right]$ plane.

The $\mathrm{g}_{\|}$feature in both the $35 \mathrm{GHz}$ and $\mathrm{X}$-band spectra of the $(\mu-\mathrm{H})_{2}$ complex exhibits a 1:2:1 splitting pattern indicative of hyperfine coupling to two magnetically equivalent $I=1 / 2$ nuclei. The splitting is $\mathrm{A} \sim 30$ gauss, or $\sim 90 \mathrm{MHz}$. The assignment of the interacting $I=1 / 2$ nuclei as protons rather than ${ }^{31} \mathrm{P}$, is established by the EPR spectrum of deuteriumsubstituted, $(\mu-\mathrm{D})_{2}, \mathbf{4}-\left(\mathbf{N}_{2}\right)_{2}$, in which the triplet splitting pattern of $\mathrm{g}_{\|}$is lost, as well as poorly-resolved hyperfine splitting at $\mathrm{g}_{\perp}$.

\section{${ }^{1} \mathrm{H}$ ENDOR of $4-\left(\mathrm{N}_{2}\right)_{2}$.}

The stochastic $\mathrm{CW}{ }^{1} \mathrm{H}$ ENDOR spectrum ${ }^{28}$ of $(\mu-\mathrm{H})_{2} \mathbf{4}-\left(\mathbf{N}_{\mathbf{2}}\right)_{2}$ collected at the single-crystallike orientation $\mathrm{g}_{1}$ (Fig 4) shows a single ${ }^{1} \mathrm{H}$ feature assigned as the $\nu_{+}\left({ }^{1} \mathrm{H}\right)$ of protons with $\mathrm{A}_{1}=86 \mathrm{MHz}$, corresponding to the large proton hyperfine coupling, $\mathrm{A}_{1} \sim 90 \mathrm{MHz}$ seen in the EPR spectrum of Figure 3. The observation of a single sharp $\nu_{+}{ }^{1} \mathrm{H}$ feature indicates that the two bridging hydrides are magnetically equivalent, as suggested by the lower-resolution EPR spectrum.

The stochastic ${ }^{2} \mathrm{H} \mathrm{CW}$ ENDOR spectra of the deuterium-substituted $(\mu-\mathrm{D})_{2}$ complex were measured, and when scaled by the ratio of the nuclear g values: $\mathrm{g}_{n}\left({ }^{1} \mathrm{H}\right) / \mathrm{g}_{\mathrm{n}}\left({ }^{2} \mathrm{H}\right)=6.514$, the observed coupling is essentially identical to the ${ }^{1} \mathrm{H}$ ENDOR coupling seen at $\mathrm{g}_{1}$, Figure 4 . 
Because the quadrupole splitting for ${ }^{2} \mathrm{H}$ is small $(\sim 100 \mathrm{kHz})$ compared to the linewidths of the $\mathrm{v}_{+/-}$features for the bridging ${ }^{2} \mathrm{H}(\sim 500 \mathrm{kHz})$, it is not resolved. The fact that the ${ }^{2} \mathrm{H}$ hyperfine interaction correlates so closely to the ${ }^{1} \mathrm{H}$ hyperfine interaction when scaled with the ratio of nuclear g-factors, $\left[\left(\mathrm{A}\left({ }^{1} \mathrm{H}\right) / \mathrm{g}\left({ }^{1} \mathrm{H}\right)\right)\right] /\left[\left(\mathrm{A}\left({ }^{2} \mathrm{H}\right): \mathrm{g}\left({ }^{2} \mathrm{H}\right)\right]=0.98\right.$, contrasts with the previous observation of a substantial isotope-induced shift in the hyperfine coupling for the terminal hydride of a Mo- ${ }^{1} \mathrm{H} /{ }^{2} \mathrm{H}$ complex, $\left[\left(\mathrm{A}\left({ }^{1} \mathrm{H}\right) / \mathrm{g}\left({ }^{1} \mathrm{H}\right)\right)\right] /\left[\left(\mathrm{A}\left({ }^{2} \mathrm{H}\right): \mathrm{g}\left({ }^{2} \mathrm{H}\right)\right]=1.14 .{ }^{32}\right.$ That hyperfine isotope effect was attributed to different Mo-H/D equilibrium distances that arise because these bonds are described by a 'soft' anharmonic potential-energy well. The essentially negligible isotope-effect on the hydride ${ }^{1 / 2} \mathrm{H}$ hyperfine couplings for $\mathbf{4}-\left(\mathbf{N}_{\mathbf{2}}\right)_{\mathbf{2}}$ instead indicates the hydrides are more tightly bound in a more-nearly-harmonic potential well.

A 2D field-frequency stochastic $\mathrm{CW}{ }^{1} \mathrm{H}$ ENDOR pattern of the $\nu_{+}$feature for the bridging hydrides was collected across the EPR envelope of $\mathbf{4}-\left(\mathbf{N}_{2}\right)_{2}$ (Fig 5). Simulation of the pattern confirms that the two hydrides are indeed magnetically equivalent, and gave a hyperfine tensor nearly coaxial with the $\mathbf{g}$-frame: principle components; $\mathbf{A}=-[87,42,70] \mathrm{MHz}$; Euler angle $(a, \beta, \gamma)=(0,10,0)$. The hyperfine tensor can be decomposed into an isotropic component $a_{i s o}=-66 \mathrm{MHz}$, and through-space electron-nuclear dipolar component $\mathbf{T}=$ $[-21,+24,-3] \mathrm{MHz}$ that closely approaches fully rhombic symmetry, $\mathbf{T} \approx[-\mathrm{t}, \mathrm{t}, 0]$. The signs of the couplings were determined by a ${ }^{1} \mathrm{H}$ PESTRE experiment (Fig S1). The negative sign of $a_{i s o}$ indicates the spin density of bridging hydrides is derived through $\left(\mathrm{d}_{\pi^{-}}-\sigma_{\mathrm{H}}\right)$ spin polarization. ${ }^{33}$

For a bridging hydride, the ${ }^{1} \mathrm{H}$ dipolar interaction tensor $\left[\mathrm{T}_{\mathrm{a}}, \mathrm{T}_{\mathrm{b}}, \mathrm{T}_{\mathrm{c}}\right]$ equals the diagonalized vector sum of the interactions with the spin density on the two individual Fe ions. Taking these interactions to be point-dipolar between the hydride nuclear spin and electron spin on the two 'anchor' $\mathrm{Fe}$ of the [Fe-H-Fe] bridge, the components of $\mathbf{T}$ have been shown to be given by eqs $3,4:^{22}$

$$
\begin{array}{r}
\tan 2 \gamma=\frac{\left[t_{1} \sin 2 \beta_{1}-t_{2} \sin 2 \beta_{2}\right]}{\left[t_{1} \cos 2 \beta_{1}+t_{2} \cos 2 \beta_{2}\right]} t_{i}=\rho_{i}\left(\frac{2 g \beta \mathrm{g}_{\mathrm{n}} \beta_{\mathrm{n}}}{r_{i}^{3}}\right) \\
T_{b}=\frac{1}{2}\left[\left(\frac{t_{1}+t_{2}}{2}\right)+\frac{3}{2} \frac{1}{\cos 2 \gamma}\left(t_{1} \cos 2 \beta_{1}+t_{2} \cos 2 \beta_{2}\right)\right] \quad T_{a}=-\frac{1}{2}\left(t_{1}+t_{2}\right) \\
T_{c}=-\left(T_{a}+T_{b}\right)
\end{array}
$$

with orientations relative to the $\mathrm{Fe}_{2} \mathrm{H}_{2}$ plane as shown in Scheme 1. With incorporation of the conclusion from the previous DFT calculations that the complex is of the type-III mixedvalence 4-( $\left.\mathbf{N}_{2}\right)_{2}$, with spin density, $\rho$, fully and equally delocalized between the two $\mathrm{Fe}$ (as supported by the ${ }^{14} \mathrm{~N}_{2}$ ENDOR results presented below), and ignoring modest delocalization to the ligands, then $\rho_{1}=\rho_{2} \approx 1 / 2 .{ }^{20}$ Incorporating the crystallographic structure parameters $\beta_{1}=33^{\circ}, r_{1}=1.69 \AA, r_{2}=1.73 \AA$, these equations (eq 3, 4) yield, $\mathbf{T}=\left[\mathrm{T}_{\mathrm{a}}, \mathrm{T}_{\mathrm{b}}, \mathrm{T}_{\mathrm{c}}\right]=[-16$, 
$18,-2] \mathrm{MHz}$ with $\gamma=2^{\circ}$, a near-perfectly rhombic tensor whose component values precisely reproduce the 'rhombic' symmetry of experiment, namely with $\mathbf{T}$ having an essentially null component and describable as $\mathbf{T} \approx[-\mathrm{t}, \mathrm{t}, 0]$, and the values are in satisfactory agreement with the experimental results $\mathbf{T}=[-21,24,-3] \mathrm{MHz}$. The correlation of calculated and experimental dipolar tensor components maps the $\mathbf{T}$ and $\mathbf{g}$ tensors onto the molecular frame as illustrated in Figure 6. The direction associated with $\mathrm{T}_{\mathrm{a}}$ and $\mathrm{g}_{1}$ is normal to the $\left[\mathrm{Fe}-\left(\mathrm{H}^{-}\right)_{2}-\mathrm{Fe}\right]$ plane, $\mathrm{T}_{\mathrm{b}}$ and $\mathrm{g}_{2}$ are normal to the $\mathrm{Fe}-\mathrm{Fe}$ bond within $\left[\mathrm{Fe}-\left(\mathrm{H}^{-}\right)_{2}-\mathrm{Fe}\right]$ planes, and $\mathrm{T}_{\mathrm{c}}$ and $\mathrm{g}_{3}$ are along Fe-Fe bond, as illustrated in Figure 6. This orientation is confirmed by the ${ }^{14} \mathrm{~N}$ ENDOR measurements on the bound $\mathrm{N}_{2}$ (see below).

The bridging hydrides of $\mathrm{E}_{4}(4 \mathrm{H})$ undergo low-temperature (10K) intra-EPR-cavity photo-

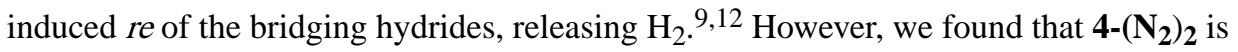
inert to such cryophotolysis.

\section{${ }^{31 P}$ ENDOR of 4-( $\left.\mathrm{N}_{2}\right)_{2}$.}

The $2 \mathrm{D}{ }^{31} \mathrm{P}$ ENDOR pattern is presented in Figure 7. The single-crystal-like spectrum at $\mathrm{g}_{1}$ exhibits two ${ }^{31} \mathrm{P}$ peaks, ${ }^{31} \mathrm{P}_{\mathrm{A}},{ }^{31} \mathrm{P}_{\mathrm{B}}$, assigned as the $\nu_{+}$partners of two similar, but distinguishable pairs of phosphorus ligand. Although the crystallographic structure shows that all four Fe-P bond lengths are similar to each other $(\sim 2.25 \AA)$, the molecular plane exhibits only an approximate inversion symmetry, with the phosphorous ligands forming two pairs of nearly equivalent nuclei, $\left[\mathrm{P}_{1}, \mathrm{P}_{4}\right],\left[\mathrm{P}_{2}, \mathrm{P}_{3}\right]$. The $\mathrm{P}$-Fe bonds within a pair are closely parallel; as depicted in the structure in Figure 6, $\angle\left(\mathrm{P}_{1}-\mathrm{Fe}_{1}-\mathrm{Fe}_{2}\right)=\angle\left(\mathrm{P}_{4}-\mathrm{Fe}_{2}-\mathrm{Fe}_{1}\right)=121^{\circ}$, whereas $\angle\left(\mathrm{P}_{2}-\mathrm{Fe}_{1}-\mathrm{Fe}_{2}\right) \approx \angle\left(\mathrm{P}_{3}-\mathrm{Fe}_{2}-\mathrm{Fe}_{1}\right) \approx 130^{\circ}$. With 4-( $\left.{ }^{\mathbf{1 4}} \mathbf{N}_{\mathbf{2}}\right)_{2}$ being a valencedelocalized complex,${ }^{20}$ the two observed ${ }^{31} \mathrm{P}$ signals are each assigned to a magnetically equivalent pair of ligands to the two $\mathrm{Fe}$, with $\left[\mathrm{P}_{1}, \mathrm{P}_{4}\right]$ arbitrarily designated as $\mathrm{P}_{\mathrm{A}},\left[\mathrm{P}_{2}, \mathrm{P}_{3}\right]$ as $\mathrm{P}_{\mathrm{B}}$. Presumably, 'steric' interactions with the hydrides contribute to the compression of the angles between the terminal P: $\angle\left(\mathrm{P}_{1}-\mathrm{Fe}_{1}-\mathrm{P}_{2}\right) \approx \angle\left(\mathrm{P}_{3}-\mathrm{Fe}_{2}-\mathrm{P}_{4}\right) \approx 110^{\circ}$.

The 2D pattern that arises from overlapping intensities from the two ${ }^{31} \mathrm{P}$ pairs was simulated with hyperfine tensors: $\mathrm{P}_{\mathrm{A}}, \mathrm{A}=+[16,25,13] \mathrm{MHz} ; \mathrm{P}_{\mathrm{B}}, \mathrm{A}=+[27,38,26] \mathrm{MHz}$. Figure 7 shows the contributions for the individual pairs; Figure $\mathrm{S} 2$ shows that the summation of the individual simulations for $\mathrm{P}_{\mathrm{A}}$ and $\mathrm{P}_{\mathrm{B}}$ matches well with the experimental spectra. The positive hyperfine sign was determined through PESTRE measurements (Fig S3), and indicates that electron delocalization is the dominant mechanism for the transfer of spin density to phosphorus. Although the isotropic couplings to the pairs are almost two-fold different, $a_{A}=+18 \mathrm{MHz}, a_{B}=+30.3 \mathrm{MHz}$, they both represent quite small spin densities on $\mathrm{P}\left(1 \mathrm{e}^{-}\right.$in a $3 s$ orbital would give $\left.a_{\text {iso }} \sim 10^{7} \mathrm{MHz}\right)$, and so the differences between the bonding to the two pairs in fact are minimal. In agreement with this, the anisotropic terms are roughly the same, $\mathbf{T} \sim[-(2-3),+(7-8),-(4-5)] \mathrm{MHz}$, with magnitudes that indicate they represent a sum of dipolar interactions with the spin delocalized to phosphorous as well as with the spin on Fe.

\section{${ }^{14} \mathrm{~N}$ ENDOR of $4-\left({ }^{14} \mathrm{~N}_{2}\right)_{2}$.}

$35 \mathrm{GHz}$ Mims pulsed ${ }^{14} \mathrm{~N}_{2}$ ENDOR spectra at the $\mathrm{g}_{3}$ single-crystal-like orientation shows four sharp signals arising from ${ }^{14} \mathrm{~N}$ of Fe-bound $\mathrm{N} \equiv \mathrm{N}$ (Fig 8). The 4-line pattern is 
characteristic of a single-crystal-like spectrum from a single type of $I=1^{14} \mathrm{~N}$ (eq $1 \mathrm{~b}$ ), but there are multiple combinations of quadrupole and hyperfine coupling that can give this pattern. To assign the peaks, we utilized the "blind spots" associated with the Mims response function, $\mathrm{R}$ (eq 2). According to the function, the signal intensity in a Mims ENDOR experiment is nulled ('blind spot') when the associated hyperfine coupling obeys the relationship, $A=n / \tau$ ( $n$ integer). ${ }^{34}$ As shown in the bottom spectrum of Figure $8, \tau=555$ ns, a 'blind' spot for $\mathrm{A}=1.8 \mathrm{MHz}$, nulls the signal response of all four peaks at once, whereas, for example, when $\tau=350 \mathrm{~ns}$ (Fig 8, top), none of the four peaks is suppressed. These observations require that the four peaks are attributed to the ${ }^{14} \mathrm{~N}$ with hyperfine coupling, $\mathrm{A}=1.8 \mathrm{MHz}$; as a result the observed pattern yields a quadrupole splitting, $\left|3 \mathrm{P}_{3}\right|=$ $2.8 \mathrm{MHz}$ (Fig 8). This response can be assigned to two equivalent $\mathrm{Fe}_{-}{ }^{14} \mathrm{~N}$ associated with the two equivalent $(\mathrm{Fe}-\mathrm{N} \equiv \mathrm{N})$ components of the valence-delocalized ${ }^{20}$ diiron core.

We assign this small hyperfine coupling to the proximal ${ }^{14} \mathrm{~N}$ of the Fe-bound $\mathrm{N} \equiv \mathrm{N}$. Given the small value of this coupling, we conclude that the hyperfine interactions with the distal ${ }^{14} \mathrm{~N}$ are even smaller, and that their ENDOR signals are not detectable. This small coupling is in fact comparable to the value seen for a nitrogenase turnover intermediate trapped during reduction of $\mathrm{N}_{2}$ and other nitrogenous substrates. In that case we concluded the $\mathrm{N}-\mathrm{N}$ bond had been cleaved and an $\mathrm{NH}_{3}$ is bound to FeMo-co. 6,7

Figure 9 presents a partial 2D field-frequency pattern of ${ }^{14} \mathrm{~N}$ ENDOR spectra collected between $\mathrm{g}_{2}$ and $\mathrm{g}_{3}$ of the EPR envelope of $\mathbf{4}-\left(\mathbf{N}_{\mathbf{2}}\right)_{2}$; the ENDOR response weakens as the field decreases from $\mathrm{g}_{2}$ toward $\mathrm{g}_{1}$ while the hyperfine coupling decreases. With the information available from the partial orientation-selective pattern, the hyperfine and quadrupole interaction tensors could nonetheless be reliably extracted by simulation of this pattern: $\mathbf{A}=-[0.1,1.8,1.8] \mathrm{MHz}, \mathbf{P}=[-1.71,0.75,0.96] \mathrm{MHz}$; both tensors coaxial with $\mathbf{g}$, $(a, \beta, \gamma)=(0,0,0)$; for a simulation of the full 2D pattern, see Figure S4. Three-pulse Xband ESEEM spectra were well simulated with the parameters derived from the ENDOR experiment with minimal adjustment, confirming the ${ }^{14} \mathrm{~N}$ ENDOR analysis (Fig S5). The ${ }^{14} \mathrm{~N}$ hyperfine tensor can be decomposed into isotropic and anisotropic components: $\mathbf{A}=$ $a_{\text {iso }} \mathbf{1}+\mathbf{T} ; a_{\text {iso }}=-1.23 \mathrm{MHz}, \mathbf{T}=+[1.13,-0.57,-0.56] \mathrm{MHz}$. The absolute signs of the hyperfine couplings, with $a_{i s o}<0$, were fixed by assuming that $\mathbf{T}$ is dominated by the dipolar interactions with spin on $\mathrm{Fe}$, which has a positive value for the unique tensor element. This assumption is validated by noting that the magnitude of the dipolar term corresponds to that expected for the through-space interaction with the spin density on the adjacent $\mathrm{Fe}$, as expected. The electric field-gradient at ${ }^{14} \mathrm{~N}$ of free $\mathrm{N}_{2}$ of course has axial symmetry, with the unique value (maximum value) along the $\mathrm{N} \equiv \mathrm{N}$ bond direction.

As the ${ }^{14} \mathrm{~N}$ quadrupole interaction exhibits this symmetry, with the quadrupole tensor component of maximum value associated with $\mathrm{g}_{1}$, this implies that the $\mathrm{Fe}-\mathrm{N} \equiv \mathrm{N}$ bond direction lies along $\mathrm{g}_{1}$. This confirms the orientation of $\mathbf{g}$ derived through use of point-dipole 'anchor' analytical model, to predict the orientation of the dipolar tensors of the bridging hydrides, Figure 6.

The nitrogen quadrupole coupling of $\mathrm{N}_{2}$ can be understood within the Townes-Dailey approximation which formulates this coupling as a function of the $\sigma$ and $\pi$ p-orbital 
populations of the bound $\mathrm{N}$. This treatment firstly shows the unique axis of the ${ }^{14} \mathrm{~N}$ quadrupole interaction (maximum coupling) corresponds to the $\mathrm{Fe}^{-1}{ }^{14} \mathrm{~N}$ bond in a linear complex, such as $4-\left(\mathbf{N}_{2}\right)_{2}$. This in turn is determined by the electrical field gradient set up by the difference between the electron occupancies of the nitrogen $2 p \sigma$ orbital (denoted $\mathrm{N}_{3}$ ), which lies along the $\mathrm{Fe}-\mathrm{N}$ bond (along $\mathrm{g}_{1}$ ), and the average of the densities in the two orthogonal $2 p \pi$ orbitals (denoted, $\mathrm{N}_{1}, \mathrm{~N}_{2}$ ). For idealized $s p$ hybridization for the coordinating ${ }^{14} \mathrm{~N}$ of $\mathrm{N}_{2}$, this field-gradient parameter can be written,

$$
\left(\mathrm{e}^{2} \mathrm{Qq} / \mathrm{h}\right) /\left(\mathrm{e}^{2} \mathrm{Qq} / \mathrm{h}\right)_{0} \equiv \Delta \mathrm{N}_{\sigma \pi}=\mathrm{N}_{\sigma}-\mathrm{N}_{\pi}=\mathrm{N}_{3}-\left(\mathrm{N}_{1}+\mathrm{N}_{2}\right) / 2 \leq 0.5
$$

where $\mathrm{e}^{2} \mathrm{Qq} / \mathrm{h}$ is the experimentally determined coupling constant and $\left(\mathrm{e}^{2} \mathrm{Qq} / \mathrm{h}\right)_{0} \sim 9.4 \mathrm{MHz}$ is the theoretical value for the contribution to the field gradient of one electron in a $p$ orbital. 35 This equation shows that $\Delta \mathrm{N}_{\sigma \pi}=0.5$ for free $\mathrm{N}_{2}$, and decreases in a metal complex through the joint action of $\sigma$-electron donation from the coordinated $\mathrm{N}$ to the metal-ion (decreasing $\mathrm{N}_{\sigma}$ ) and $\pi$-electron back-donation from the metal-ion (increasing $\mathrm{N}_{\pi}$ ).

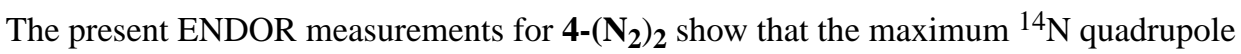
coupling, and thus the $\mathrm{Fe}^{14}{ }^{14}$ bond, lies along $\mathrm{g}_{1}$, in agreement with the conclusion from ENDOR of the bridging hydrides. The maximum coupling yields the quadrupole coupling field-gradient parameter $\left(\mathrm{e}^{2} \mathrm{Qq} / \mathrm{h}\right)$,

$$
\left(e^{2} Q q / h\right)=2 P_{\max }=-3.42 \mathrm{MHz} .
$$

and thus, according to eq 5 , the measured value of $\mathrm{e}^{2} \mathrm{Qq} / \mathrm{h}$ for Fe- ${ }^{14} \mathrm{~N}$ yields, $\Delta \mathrm{N}_{\sigma \pi}=0.36$. In short, the net effect of Fe-N bond formation is to enhance to $2 \mathrm{p} \pi$-electron population relative to the $2 \mathrm{p} \sigma$-electron population by $\sim 0.14$ electrons.

\section{Conclusions}

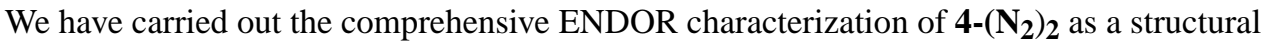
model complex of the Janus intermediate, $\mathrm{E}_{4}(4 \mathrm{H})$ which has accumulated $4[\mathrm{e}-/ \mathrm{H}+]$, stored as two [Fe-H-Fe] bridging hydrides and as a possible state along a proposed pathway for re of $\mathrm{H}_{2}$ and $\mathrm{N}_{2}$ binding in nitrogenase. As outlined in the introduction, the nitrogenase Janus intermediate, $\mathrm{E}_{4}(4 \mathrm{H})$, has accumulated $4\left[\mathrm{e}^{-} / \mathrm{H}^{+}\right]$, stored as two $[\mathrm{Fe}-\mathrm{H}-\mathrm{Fe}]$ bridging hydrides, and is activated to bind and reduce $\mathrm{N}_{2}$ through re of the hydrides as $\mathrm{H}_{2} \cdot{ }^{1} \mathrm{H}$, and ${ }^{14} \mathrm{~N}$ ENDOR measurements confirm that this formally ' $\mathrm{Fe}(\mathrm{II}) / \mathrm{Fe}(\mathrm{I})$ ' complex exhibits a fully delocalized, Robin-Day type III mixed valency. The two bridging hydrides exhibit a fully rhombic dipolar interaction with the electron spin, $\mathbf{T} \approx[-\mathrm{t},+\mathrm{t}, 0]$, as predicted by the 'anchor-model', point-dipole eqs 3, 4 with input from the structure of the complex. The ${ }^{1} \mathrm{H}$ measurements as interpreted through eqs 3, 4 and Scheme 1, further map the $\mathrm{g}$ tensor onto the molecular frame, Figure 6, and this mapping has been confirmed by its agreement with the orientation of the ${ }^{14} \mathrm{~N}$ quadrupole interaction tensor of bound $\mathrm{N}_{2}$. This agreement supports the conclusion that a rhombic ${ }^{1} \mathrm{H}$ hyperfine interaction provides a diagnostic 
signature that can be used to identify an [Fe-H-Fe] structure in biological systems, including nitrogenases and hydrogenases, and that the anchor model reveals its orientation relative to the molecular frame. Indeed, the original assignment of two bridging hydrides in the nitrogenase $\mathrm{E}_{4}(4 \mathrm{H})$ intermediate was based on assigning the signature rhombic dipolar tensor.

The complex 4-( $\left.\mathbf{N}_{2}\right)_{2}$ also serves as a model of the intermediate invoked in the 'Associative' pathway for $r e$, in which $\mathrm{E}_{4}(4 \mathrm{H})$ binds $\mathrm{N}_{2}$ prior to formation and release of $\mathrm{H}_{2}$, Figure 2. Of fundamental chemical significance, the ${ }^{14} \mathrm{~N}$ quadrupole coupling constant gives a quantitative estimate of the amount of charge transferred between $\mathrm{Fe}$ and the coordinated ${ }^{14} \mathrm{~N}$ of $\mathrm{N}_{2}$, a key indicator of ${ }^{14} \mathrm{~N}$ activation for reduction: the net effect of $\mathrm{Fe}-\mathrm{N}$ bond formation in $4-\left(\mathbf{N}_{2}\right)_{2}$ is to enhance $2 \mathrm{p} \pi$-electron population relative to the $2 \mathrm{p} \sigma$-electron population by $\sim 0.14$ electrons.

\section{Supplementary Material}

Refer to Web version on PubMed Central for supplementary material.

\section{ACKNOWLEDGMENTS}

This work was supported by the NIH (GM 075757 to J.C.P) and the NSF (MCB 1515981 to B.M.H). We thank Dr. Peter Doan for insightful ENDOR discussions.

\section{References}

(1). Burgess BK; Lowe DJ Mechanism of Molybdenum Nitrogenase. Chem Rev 1996, 96, 2983-3012. [PubMed: 11848849]

(2). Seefeldt LC; Hoffman BM; Dean DR Mechanism of Mo-Dependent Nitrogenase. Annu. Rev. Biochem 2009, 78, 701-722. [PubMed: 19489731]

(3). Christiansen J; Seefeldt LC; Dean DR Competitive Substrate and Inhibitor Interactions at the Physiologically Relevant Active Site of Nitrogenase. J. Biol. Chem 2000, 275, 36104-36107. [PubMed: 10948195]

(4). Kim C-H; Newton WE; Dean DR Role of the Mofe Protein a-Subunit Histidine-195 Residue in Femo-Cofactor Binding and Nitrogenase Catalysis. Biochemistry 1995, 34, 2798-2808. [PubMed: 7893691]

(5). Barney BM; Igarashi RY; Dos Santos PC; Dean DR; Seefeldt LC Substrate Interaction at an IronSulfur Face of the Femo-Cofactor During Nitrogenase Catalysis. J. Biol. Chem 2004, 279, 53621-53624. [PubMed: 15465817]

(6). Hoffman BM; Lukoyanov D; Yang ZY; Dean DR; Seefeldt LC Mechanism of Nitrogen Fixation by Nitrogenase: The Next Stage. Chem Rev 2014, 114, 4041-4062. [PubMed: 24467365]

(7). Hoffman BM; Lukoyanov D; Dean DR; Seefeldt LC Nitrogenase: A Draft Mechanism. Acc. Chem. Res 2013, 46, 587-595. [PubMed: 23289741]

(8). Lukoyanov D; Yang ZY; Khadka N; Dean DR; Seefeldt LC; Hoffman BM Identification of a Key Catalytic Intermediate Demonstrates That Nitrogenase Is Activated by the Reversible Exchange of $\mathrm{N}_{2}$ for $\mathrm{H}_{2}$. J. Am. Chem. Soc 2015, 137, 3610-3615. [PubMed: 25741750]

(9). Lukoyanov D; Khadka N; Yang ZY; Dean DR; Seefeldt LC; Hoffman BM Reductive Elimination of $\mathrm{H} 2$ Activates Nitrogenase to Reduce the N三N Triple Bond: Characterization of the E4(4h) Janus Intermediate in Wild-Type Enzyme. J. Am. Chem. Soc 2016, 138, 10674-10683. [PubMed: 27529724]

(10). Igarashi RY; Laryukhin M; Dos Santos PC; Lee HI; Dean DR; Seefeldt LC; Hoffman BM Trapping H- Bound to the Nitrogenase Femo-Cofactor Active Site During H2 Evolution: 
Characterization by Endor Spectroscopy. J. Am. Chem. Soc 2005, 127, 6231-6241. [PubMed: 15853328]

(11). Yang Z-Y; Khadka N; Lukoyanov D; Hoffman Brian M; Dean Dennis R; Seefeldt Lance C On Reversible H2 Loss Upon N2 Binding to Femo-Cofactor of Nitrogenase. PNAS 2013, 110, 16327-16332. [PubMed: 24062454]

(12). Lukoyanov D; Khadka N; Yang ZY; Dean DR; Seefeldt LC; Hoffman BM Reversible Photoinduced Reductive Elimination of H2 from the Nitrogenase Dihydride State, the E4(4h) Janus Intermediate. J. Am. Chem. Soc 2016, 138, 1320-1327. [PubMed: 26788586]

(13). Lukoyanov D; Khadka N; Dean DR; Raugei S; Seefeldt LC; Hoffman BM Photoinduced Reductive Elimination of H2 from the Nitrogenase Dihydride (Janus) State Involves a FemoCofactor-H2 Intermediate. Inorg. Chem 2017, 56, 2233-2240. [PubMed: 28177622]

(14). Lukoyanov D; Dikanov SA; Yang ZY; Barney BM; Samoilova RI; Narasimhulu KV; Dean DR; Seefeldt LC; Hoffman BM Endor/Hyscore Studies of the Common Intermediate Trapped During Nitrogenase Reduction of $\mathrm{N}_{2} \mathrm{~h}_{2}, \mathrm{Ch}_{3} \mathrm{n}_{2} \mathrm{~h}$, and $\mathrm{N}_{2} \mathrm{~h}_{4}$ Support an Alternating Reaction Pathway for $\mathrm{N}_{2}$ Reduction. J. Am. Chem. Soc 2011, 133, 11655-11664. [PubMed: 21744838]

(15). Smith JM; Lachicotte RJ; Pittard KA; Cundari TR; Lukat-Rodgers G; Rodgers KR; Holland PL Stepwise Reduction of Dinitrogen Bond Order by a Low-Coordinate Iron Complex. J. Am. Chem. Soc 2001, 123, 9222-9223. [PubMed: 11552855]

(16). Betley TA; Peters JC Dinitrogen Chemistry from Trigonally Coordinated Iron and Cobalt Platforms. J. Am. Chem. Soc 2003, 125, 10782-10783. [PubMed: 12952446]

(17). Creutz SE; Peters JC Diiron Bridged-Thiolate Complexes That Bind $\mathrm{N}_{2}$ at the $\mathrm{Fe}^{\mathrm{ii}} \mathrm{fe}^{\mathrm{ii}}, \mathrm{Fei}^{\mathrm{i}} \mathrm{fe}^{\mathrm{i}}$, and $\mathrm{Fe}^{\mathrm{i}} \mathrm{fe}^{\mathrm{i}}$ Redox States. J. Am. Chem. Soc 2015, 137, 7310-7313. [PubMed: 26039253]

(18). Rodriguez MM; Bill E; Brennessel WW; Holland PL N2 Reduction and Hydrogenation to Ammonia by a Molecular Iron-Potassium Complex. Science 2011, 334, 780-783. [PubMed: 22076372]

(19). Saouma CT; Müller P; Peters JC Characterization of Structurally Unusual Diiron $\mathrm{N}_{\mathrm{x}} \mathrm{h}_{\mathrm{y}}$ Complexes. J. Am. Chem. Soc 2009, 131, 10358-10359. [PubMed: 19722612]

(20). Rittle J; McCrory CCL; Peters JCA $10^{6}$-Fold Enhancement in $\mathrm{N}_{2}$-Binding Affinity of an $\mathrm{Fe}_{2}$ (M$\mathrm{H})_{2}$ Core Upon Reduction to a Mixed-Valence $\mathrm{Fe}^{\mathrm{ii}} \mathrm{fe}^{\mathrm{i}}$ State. J. Am. Chem. Soc 2014, 136, 13853-13862. [PubMed: 25184795]

(21). Oliver Science paper 2018

(22). Willems J-P; Lee H-I; Burdi D; Doan PE; Stubbe J; Hoffman BM Identification of the Protonated Oxygenic Ligands of Ribonucleotide Reductase Intermediate $\mathrm{X}$ by Q-Band ${ }^{1,2} \mathrm{~h} \mathrm{Cw}$ and Pulsed Endor. J. Am. Chem. Soc 1997, 119, 9816-9824.

(23). Kinney RA; Saouma CT; Peters JC; Hoffman BM Modeling the Signatures of Hydrides in Metalloenzymes: Endor Analysis of a Di-Iron Fe(Mu-Nh)(Mu-H)Fe Core. J. Am. Chem. Soc 2012, 134, 12637-12647. [PubMed: 22823933]

(24). Werst MM; Davoust CE; Hoffman BM Ligand Spin Densities in Blue Copper Proteins by QBand ${ }^{1} \mathrm{~h}$ and ${ }^{14} \mathrm{n}$ Endor Spectroscopy. J. Am. Chem. Soc 1991, 113, 1533-1538.

(25). Zipse H; Artin E; Wnuk S; Lohman GJS; Martino D; Griffin RG; Kacprzak S; Kaupp M; Hoffman B; Bennati M; Stubbe J; Lees N Structure of the Nucleotide Radical Formed During Reaction of Cdp/Ttp with the E441q-A2 32 of E. Coli Ribonucleotide Reductase. J. Am. Chem. Soc 2009, 131, 200-211. [PubMed: 19128178]

(26). Davoust CE; Doan PE; Hoffman BM Q-Band Pulsed Electron Spin-Echo Spectrometer and Its Application to Endor and Eseem. J. Magn. Reson 1996, 119, 38-44.

(27). Hoffman BM; DeRose VJ; Ong JL; Davoust CE Sensitivity Enhancement in Field-Modulated Cw Endor Via Rf Bandwidth Broadening. J. Magn. Reson 1994, 110, 52-57.

(28). Lee H-I; Igarashi RY; Laryukhin M; Doan PE; Dos Santos PC; Dean DR; Seefeldt LC; Hoffman BM An Organometallic Intermediate During Alkyne Reduction by Nitrogenase. J. Am. Chem. Soc 2004, 126, 9563-9569. [PubMed: 15291559]

(29). Hoffman BM Electron Nuclear Double Resonance (Endor) of Metalloenzymes. Acc. Chem. Res 1991, 24, 164-170. 
(30). Doan PE: The Past, Present, and Future of Orientation-Selected Endor Analysis: Solving the Challenges of Dipolar-Coupled Nuclei. In Paramagnetic Resonance of Metallobiomolecules; Telser J, Ed.; American Chemical Society, 2003; pp 55-81.

(31). Doan PE Combining Steady-State and Dynamic Methods for Determining Absolute Signs of Hyperfine Interactions: Pulsed Endor Saturation and Recovery (Pestre). J. Magn. Reson 2011, 208, 76-86. [PubMed: 21075026]

(32). Kinney RA; Hetterscheid DGH; Hanna BS; Schrock RR; Hoffman BM Formation of $\left\{[\text { Hiptn3n]Mo(Iii)H }\}^{-}\right.$by Heterolytic Cleavage of $\mathrm{H}_{2}$ as Established by Epr and Endor Spectroscopy. Inorg. Chem 2010, 49, 704-713. [PubMed: 20000748]

(33). Weil JA; Bolton JR; Wertz JE: Electron Paramagnetic Resonance: Elementary Theory and Practical Applications; John Wiley \& Sons, Inc: New York, 1994.

(34). Doan PE; Lees NS; Shanmugam M; Hoffman BM Simulating Suppression Effects in Pulsed Endor, and the 'Hole in the Middle' of Mims and Davies Endor Spectra. Appl. Magn. Reson 2010, 37, 763-779. [PubMed: 20161480]

(35). Lucken EAC: Nuclear Quadrupole Coupling Constants; Academic Press: New York, 1969. 


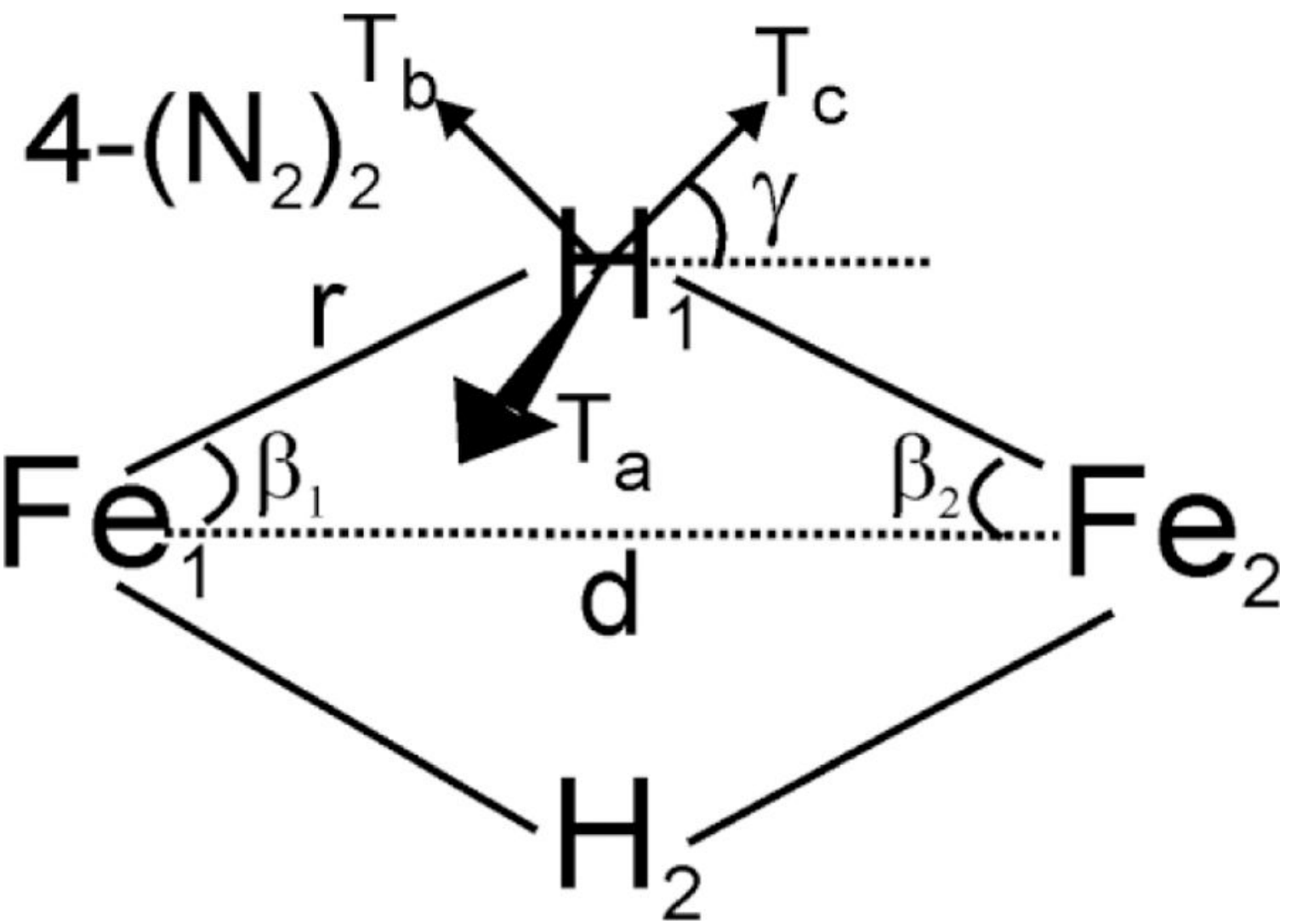

Scheme 1.

Schematic representation of metric parameters used to calculate the proton dipolar tensor within the defined molecular frame. 


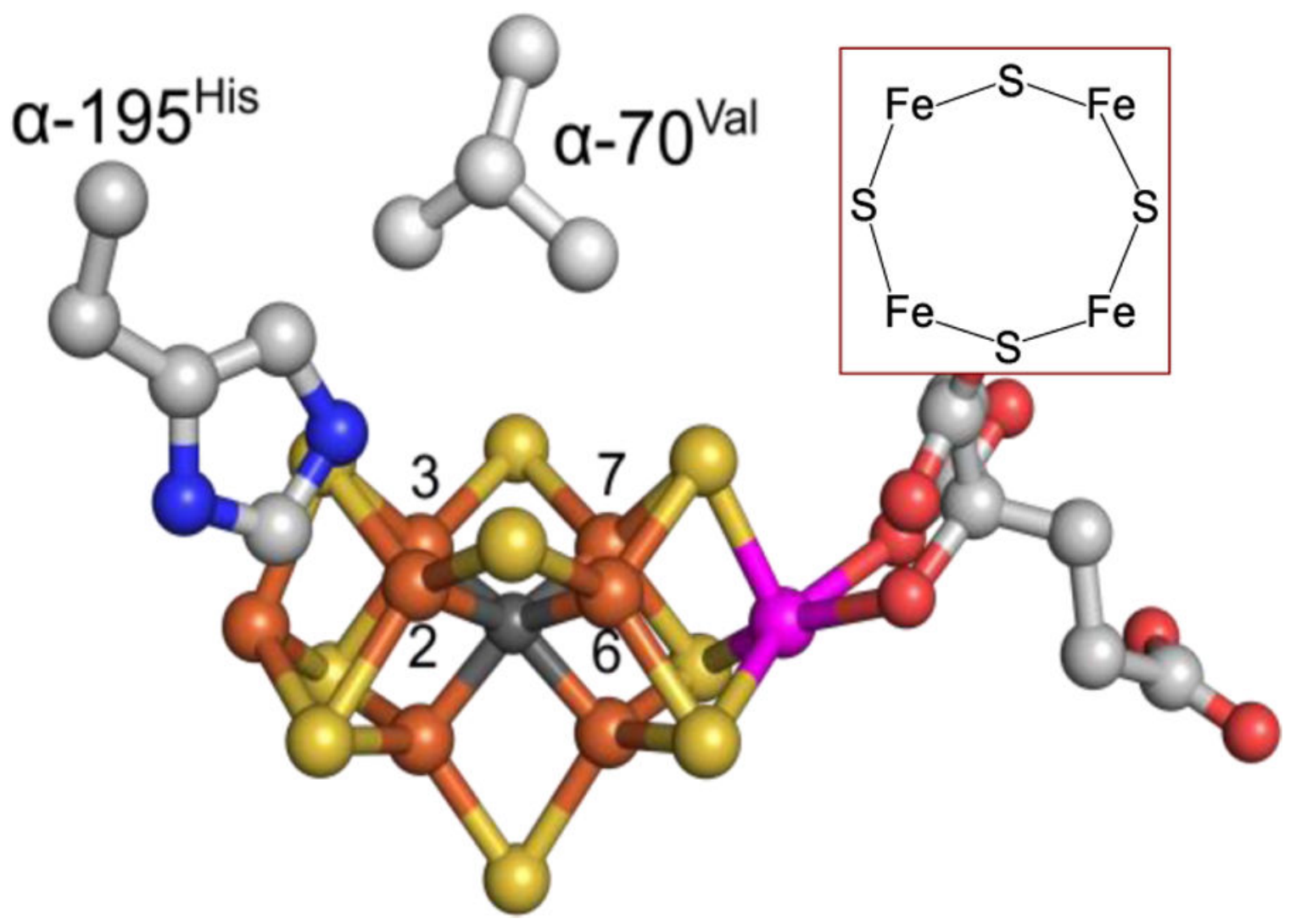

Figure 1.

FeMo-co, [7Fe-9S-Mo-C-homocitrate] with cartoon of active Fe 2,3,6,7 FeMo-co face. PDB, 2AFI. 


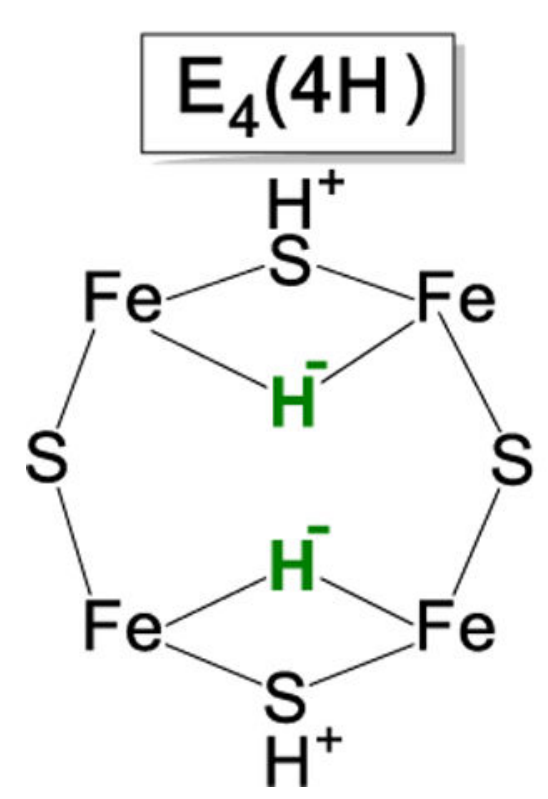

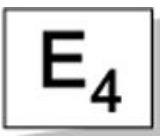
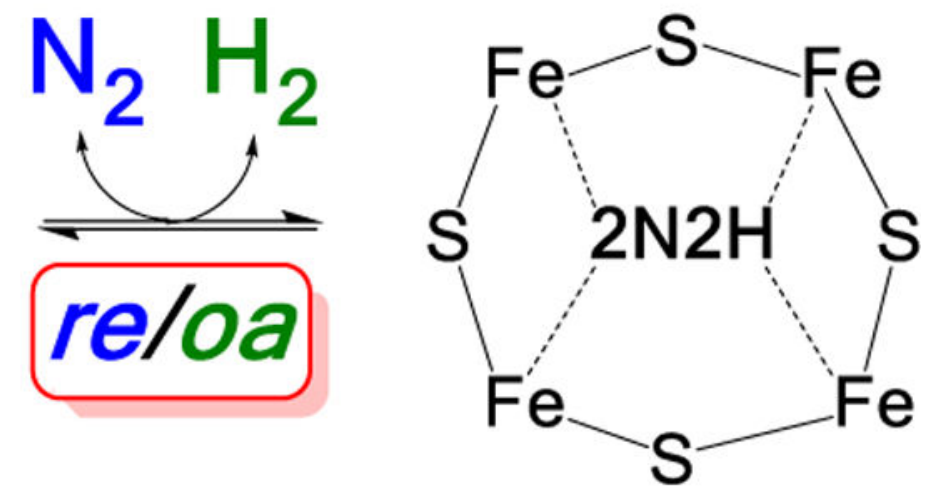

Figure 2. Schematic of re/oa:

Fe 2,3,6,7 FeMo-co face. The positioning of hydrides is a matter of current investigation and shown is our current best guess; likewise for position of protons in $\mathrm{E}_{4}(4 \mathrm{H})$ and the hemilability of bridging sulfur (see text); '2N2H' denotes a diazene-level intermediate. 


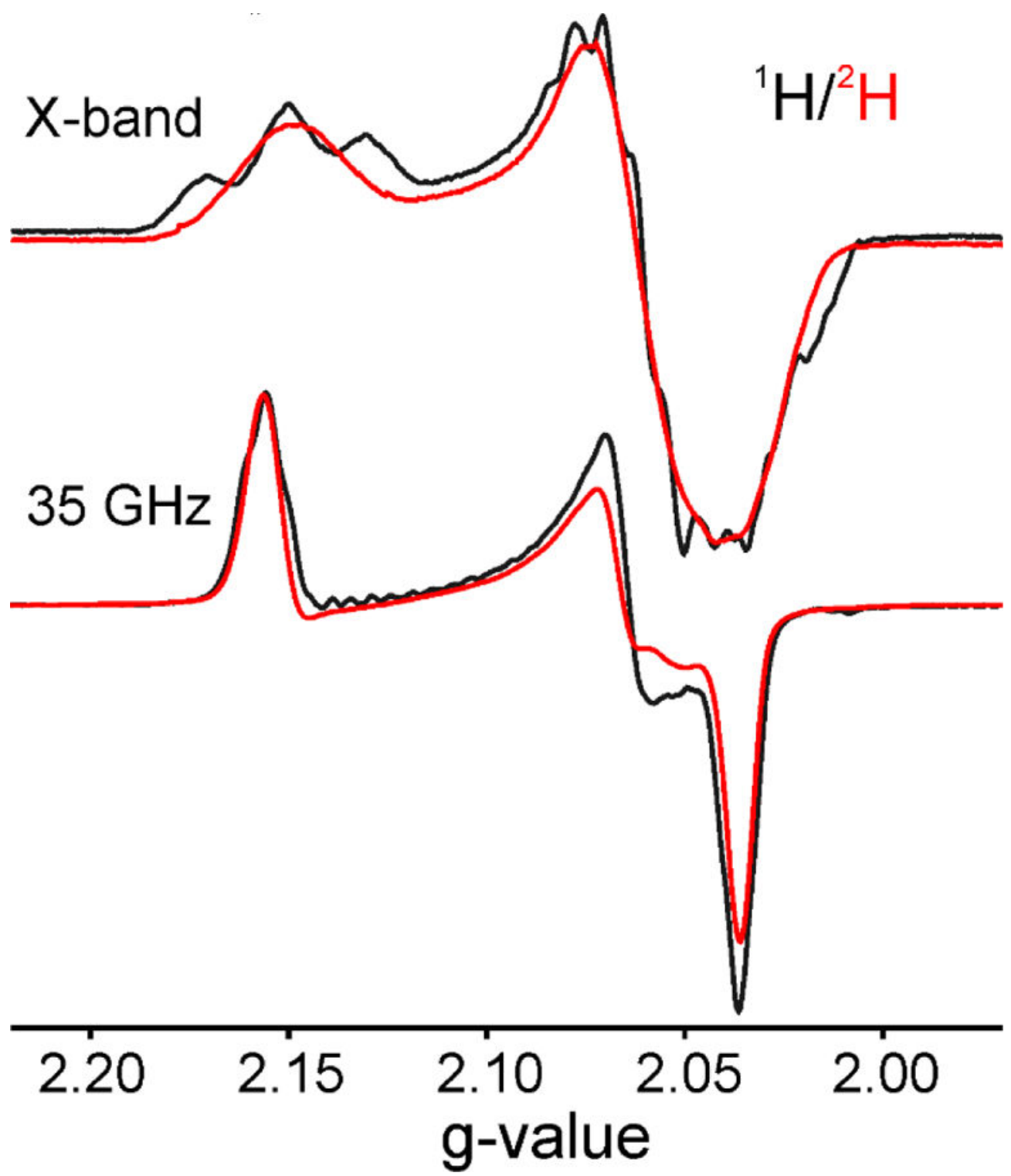

Figure 3.

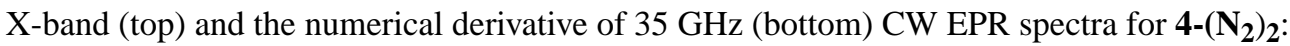
(black) $\left(\mu-{ }^{1} \mathrm{H}\right)_{2} ;($ red $\left.)\left(\mu-{ }^{2} \mathrm{H}\right)_{2}\right)$. Experimental conditions: X-band, microwave frequency, $9.215 \mathrm{GHz}$, modulation amplitude, $10 \mathrm{G}$; temperature, $77 \mathrm{~K}$. '35 GHz' microwave frequency, $35.084 \mathrm{GHz}$; microwave power, $10 \mu \mathrm{W}$; modulation amplitude $2 \mathrm{G}$; time constant, $32 \mathrm{~ms}$; temperature, $2 \mathrm{~K}$. 

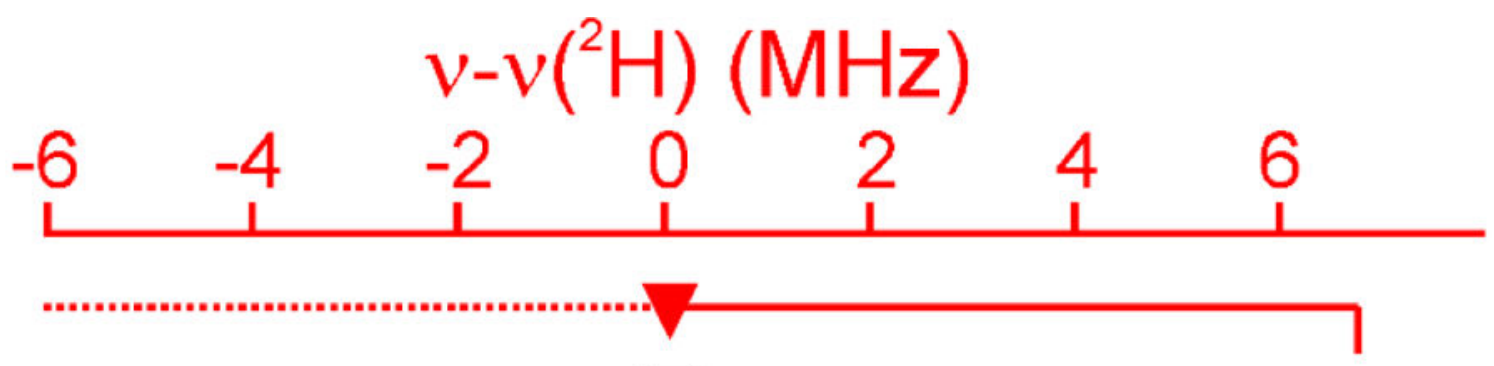

$\mathrm{A}\left({ }^{1} \mathrm{H}\right)=86 \mathrm{MHz}$
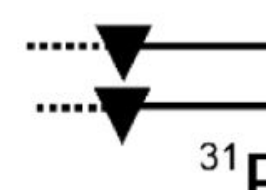

$-40-30-20-10$ $v-v\left({ }^{1} \mathrm{H}\right)(\mathrm{MHz})$

Figure 4.

$35 \mathrm{GHz}$ stochastic $\mathrm{CW}{ }^{1} \mathrm{H}$ (black) and ${ }^{2} \mathrm{H}$ (red) ENDOR spectra at $\mathrm{g}_{1}$ for $\mathbf{4}-\left(\mathbf{N}_{\mathbf{2}}\right)_{\mathbf{2}}$.

Experimental conditions: sample time, $0.75 \mathrm{~ms}$; delay time, $0.5 \mathrm{~ms}$; RF-on time, $0.5 \mathrm{~ms}$; modulation amplitude, $4 \mathrm{G}$; microwave frequency, $35.084 \mathrm{GHz}$; microwave power, $10 \mu \mathrm{W}$; temperature $2 \mathrm{~K}$. $(*)$ in ${ }^{2} \mathrm{H}$ ENDOR spectrum indicates $\nu_{-}$of ${ }^{31} \mathrm{P}_{\mathrm{A}}$. 

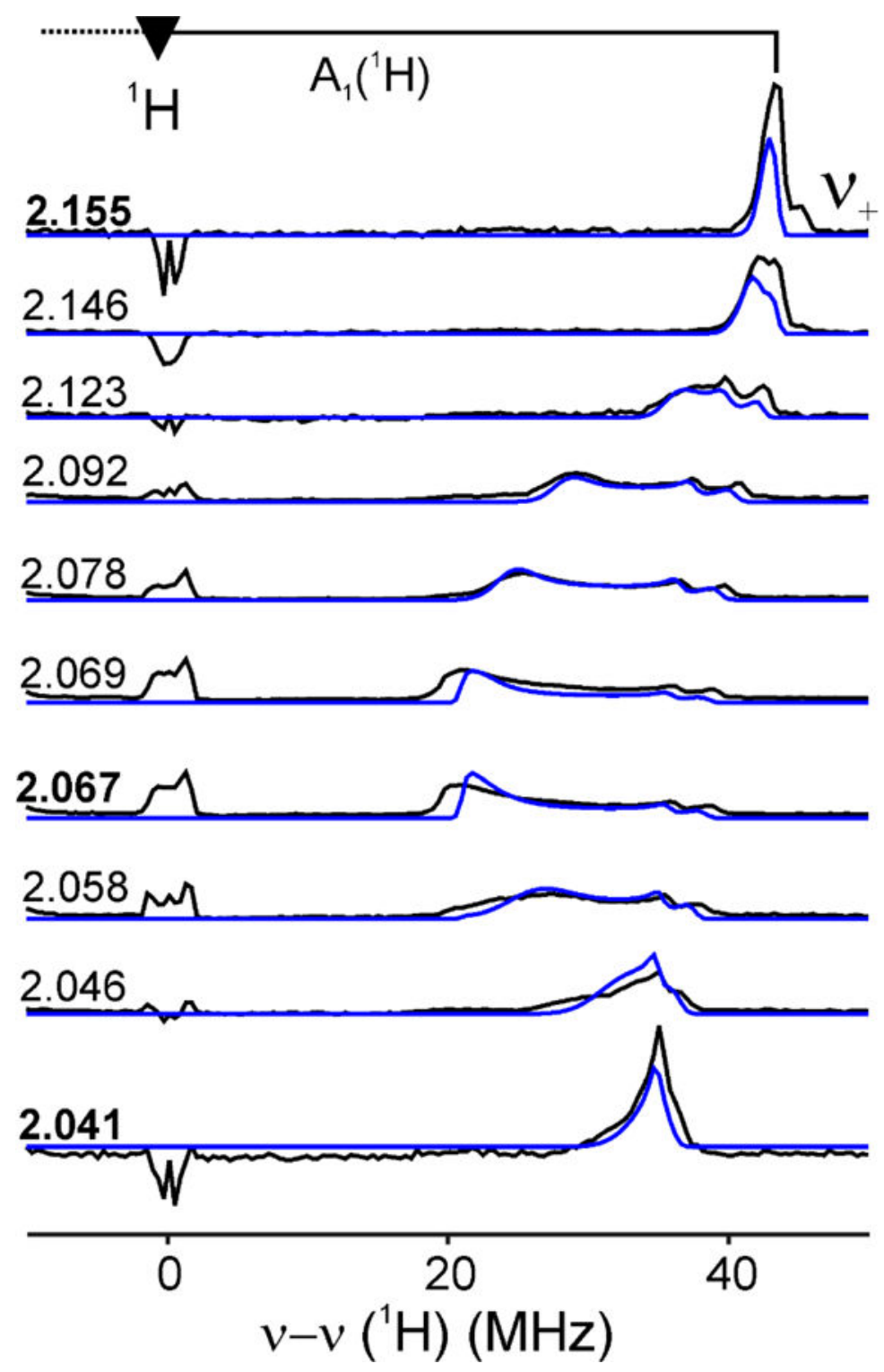

Figure 5.

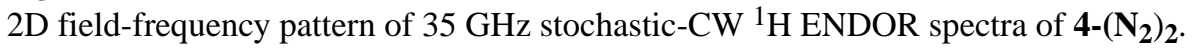
Experimental conditions: sample time, $0.75 \mathrm{~ms}$; delay time, $0.5 \mathrm{~ms}$; RF-on time, $0.5 \mathrm{~ms}$; modulation amplitude, $4 \mathrm{G}$; microwave frequency, $35.084 \mathrm{GHz}$; microwave power, $10 \mu \mathrm{W}$; temperature 2K. Simulation (Blue): $\mathbf{g}=[2.155,2.067,2.038], \mathbf{A}=[87,42,70] \mathrm{MHz}$, and $(\mathbf{a}$, $\beta, \gamma)=(0,10,0)$. 


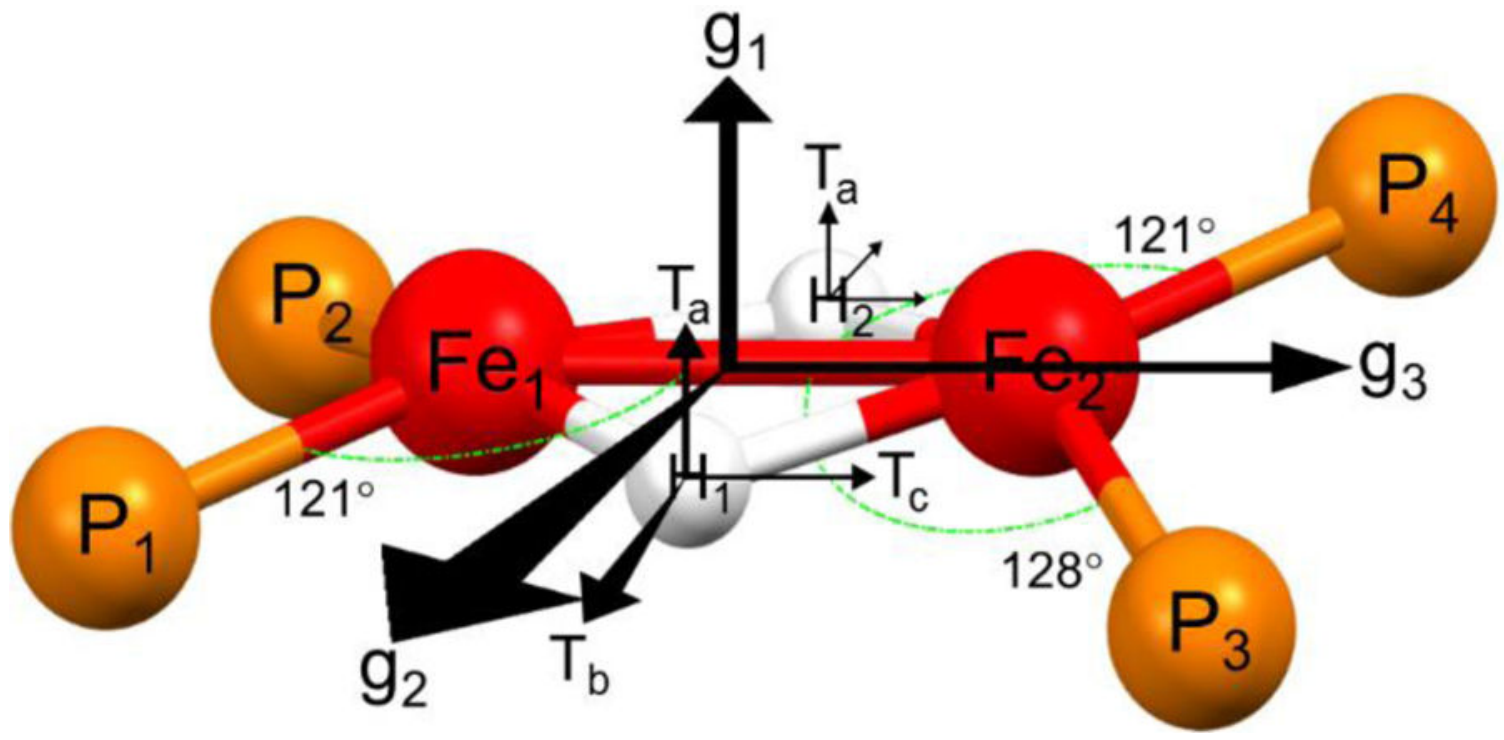

Figure 6.

Core structure of 4-( $\left.\mathbf{N}_{2}\right)_{2}$ superimposed with $\mathbf{g}$-frame and dipolar tensor $\mathbf{T}$-frame of bridging hydrides. 

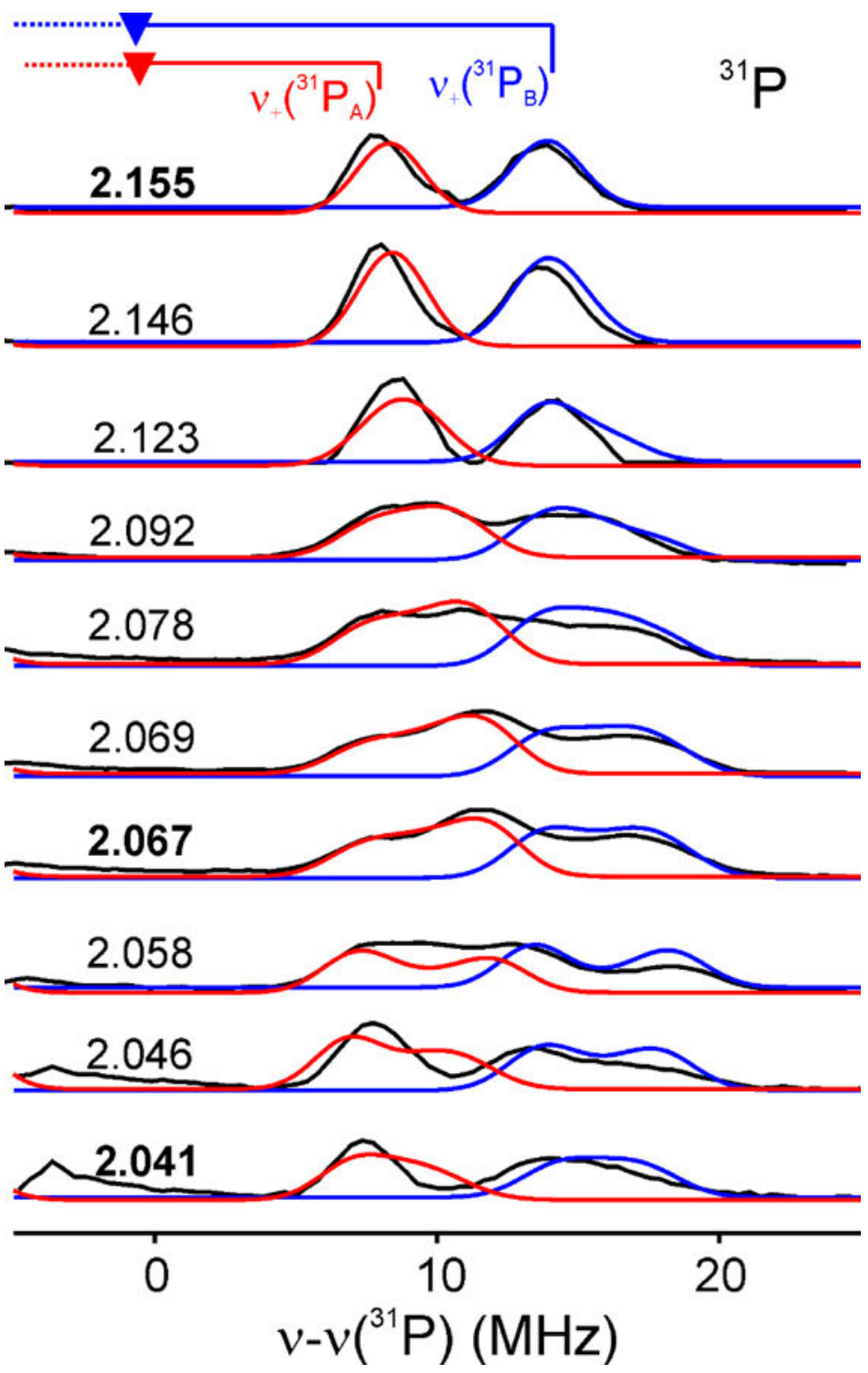

Figure 7.

2D pattern of stochastic ${ }^{31} \mathrm{P}$ ENDOR (Black) and the simulation of $\mathrm{P}_{\mathrm{A}}$ (red) and $\mathrm{P}_{\mathrm{B}}$ (blue). Experimental conditions: sample time, $0.75 \mathrm{~ms}$; delay time, $0.5 \mathrm{~ms}$; RF-on time, $0.5 \mathrm{~ms}$; modulation amplitude, $4 \mathrm{G}$; microwave frequency, $35.084 \mathrm{GHz}$; microwave power, $10 \mu \mathrm{W}$; temperature $2 \mathrm{~K}$. Simulation: $\mathrm{P}_{\mathrm{A}}, \mathrm{A}=+[16.5,25,13] \mathrm{MHz},(\alpha, \beta, \gamma)=(30,10,0) ; \mathrm{P}_{\mathrm{B}}, \mathrm{A}=$ $+[27,38,26] \mathrm{MHz},(\mathrm{a}, \beta, \gamma)=(45,20,0)$. 

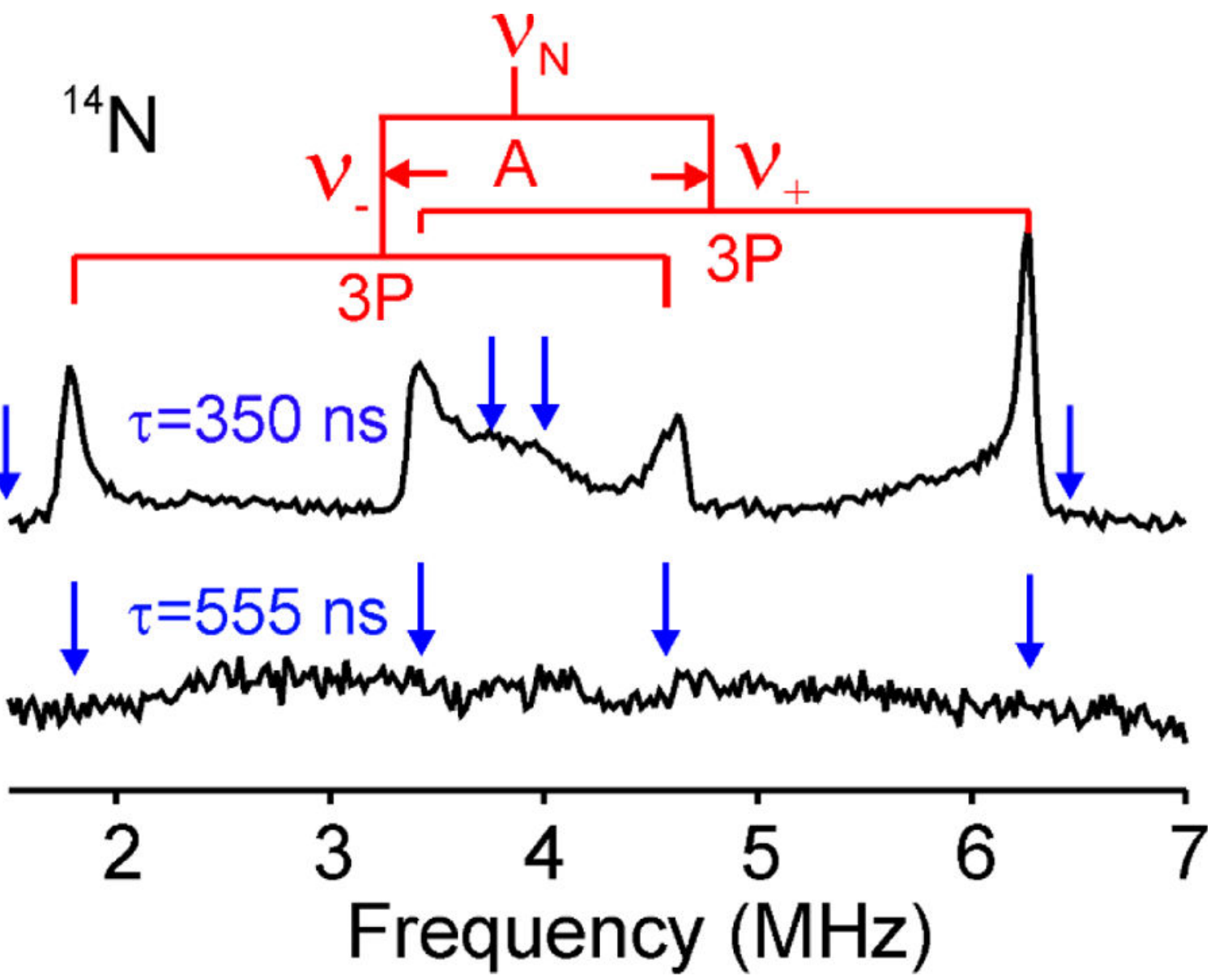

Figure 8.

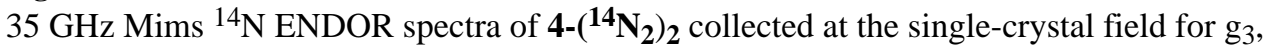
showing suppression of the entire ${ }^{14} \mathrm{~N}$ signal when $\tau=1 / \mathrm{A}$ (eq 2): Upper/Lower spectra, $\tau=$ $350 / 555 \mathrm{~ns}$. The signal intensities of the two spectra are normalized to their 2-pulse ESE intensity. Experimental conditions: microwave frequency, $35.075 \mathrm{GHz} ; \pi / 2=30 \mathrm{~ns} ; \mathrm{t}_{\mathrm{RF}}=60$ $\mu \mathrm{s}$, and $\mathrm{RF}$ randomly hopped; repetition time, $25 \mathrm{~ms}$; temperature, $2 \mathrm{~K}$. The arrows represent Mims-hole suppression pattern. 

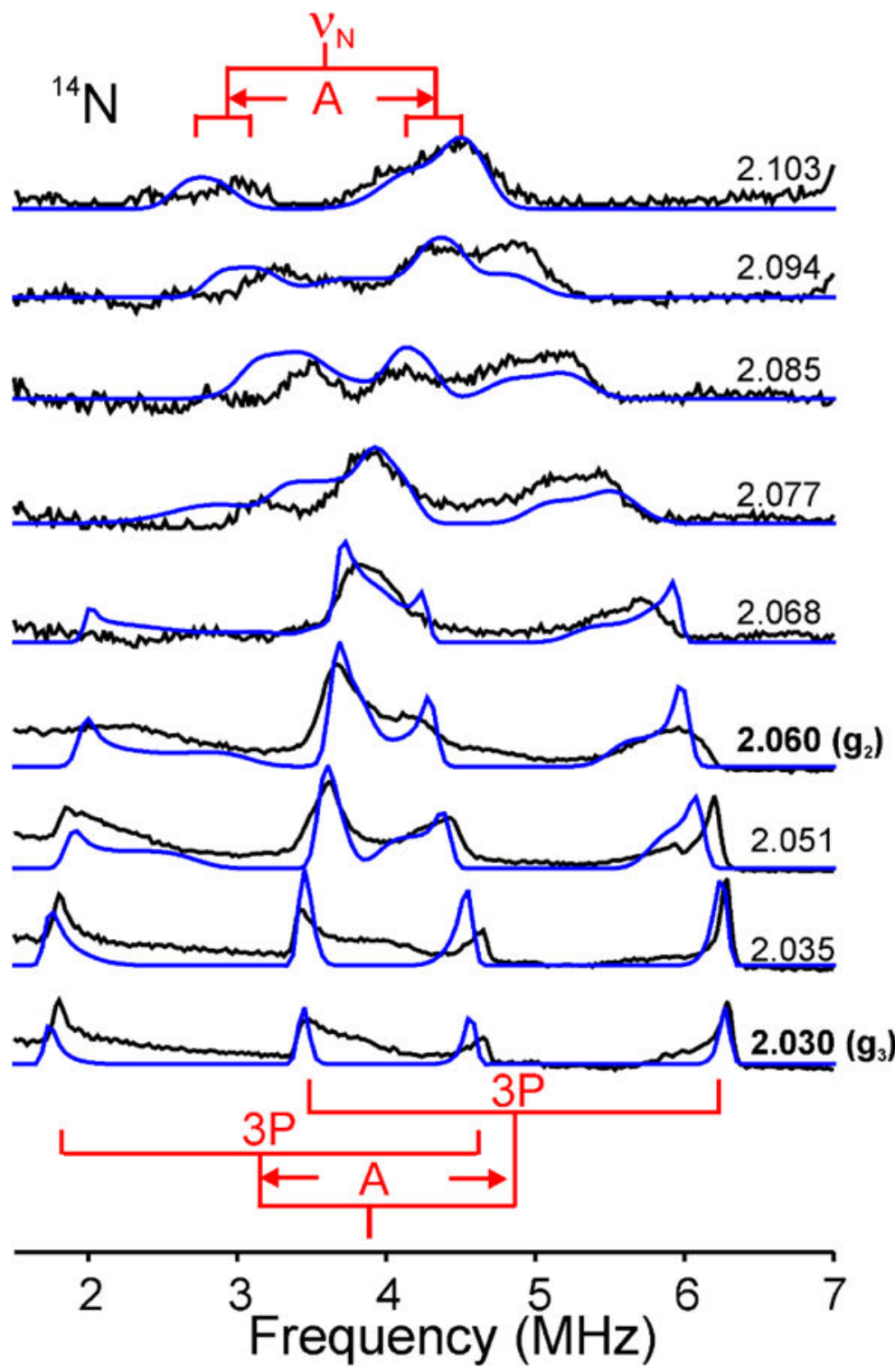

Figure 9.

Partial 2D field-frequency $35 \mathrm{GHz}$ Mims ${ }^{14} \mathrm{~N}$ ENDOR spectra of $\mathbf{4}-\left(\mathbf{N}_{\mathbf{2}}\right)_{\mathbf{2}}$ (black).

Experimental conditions: microwave frequency, $35.075 \mathrm{GHz} ; \pi / 2=30 \mathrm{~ns} ; \tau=350 \mathrm{~ns} ; \mathrm{t}_{\mathrm{RF}}=$ $60 \mu$ s, and RF randomly hopped; repetition time, $25 \mathrm{~ms}$; temperature, 2K. Simulations (blue): $\mathbf{A}=[0.1,1.8,1.8] \mathrm{MHz}, \mathbf{P}=[-1.71,0.75,0.96] \mathrm{MHz},(\alpha, \beta, \gamma)=(0,0,0)$. 


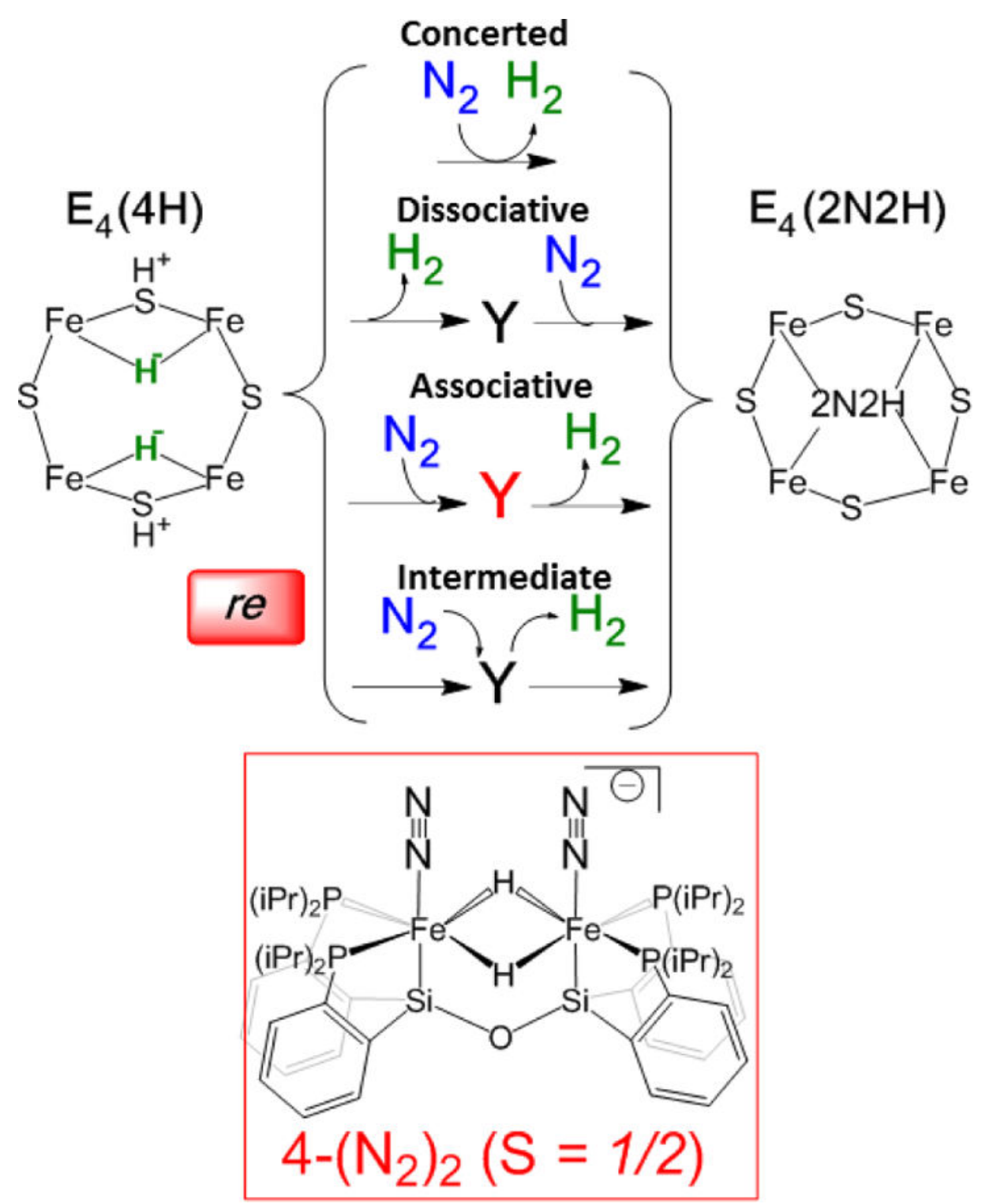

Chart 1 